\title{
DRAMATURGIAS DE DESVIO: UM ESTUDO COMPARATIVO DE TEXTOS ENCENADOS NO BRASIL
}

RESUMO

$O$ artigo apresenta uma sintese da tese Dramaturgias de desvio: recorrências em textos encenados no Brasil entre 1995 e 2015, estudo comparativo de cem peças montadas em cidades de diferentes regiões brasileiras. O texto expõe os principais tópicos da pesquisa e suas perspectivas teóricas, com o objetivo de propor caminhos para o mapeamento da produção dramatúrgica contemporânea.

Palavras-chave:

Dramaturgia; Desvio; Cena contemporânea. 


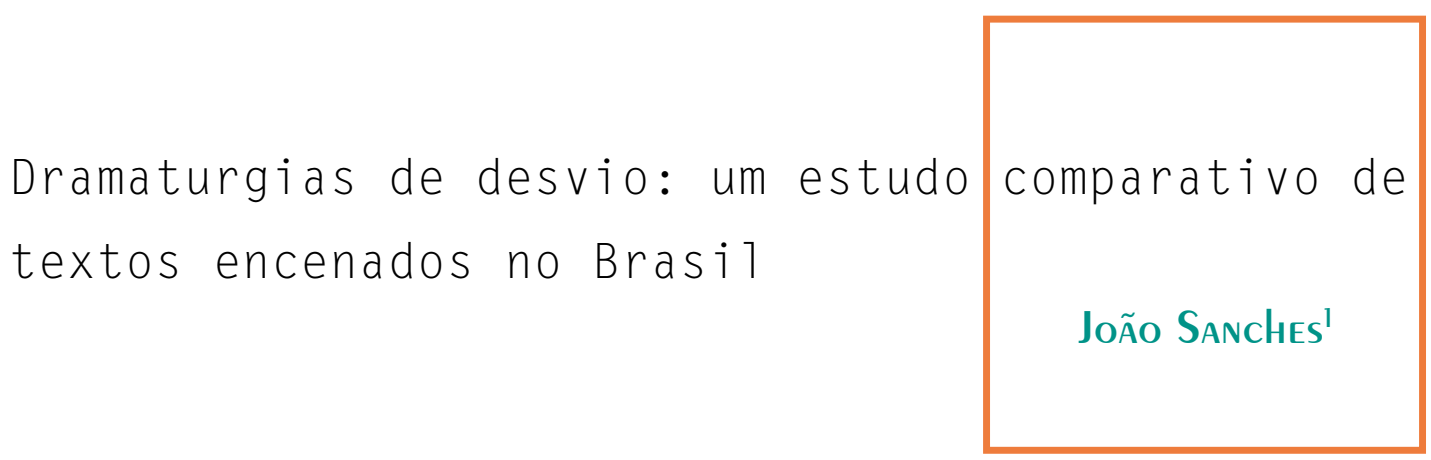

\footnotetext{
${ }^{1}$ João Sanches (João Alberto Lima Sanches) é dramaturgo, encenador e iluminador. Doutor em Artes Cênicas (PPGAC - UFBA) e professor do Centro de Cultura, Linguagens e Tecnologias Aplicadas (CECULT) da Universidade Federal do Recôncavo da Bahia (UFRB).
}

Os autores dramáticos e os respectivos críticos têm um vocábulo em comum: poética. Esta "poética", os dramaturgos fundam-na empiricamente através da diversidade das suas obras, e os estetas do teatro procuram atribuir-lhe uma acepção geral e uma formulação teórica. Enquanto que os primeiros inventam, numa determinada época, os possiveis da sua arte, os segundos trabalham, geralmente a posteriori, no sentido de delimitar o campo dos possíveis. Mas será que esta abordagem hesitante das dramaturgias imediatamente contemporâneas merece o título de poética? Poderse-á fixar, através do discurso crítico, o que existe apenas num estado incoativo, o que apenas teve tempo de começar? (SARRAZAC, 2002, p. 23).

Em O futuro do drama (SARRAZAC, 2002), o dramaturgo e pesquisador francês Jean-Pierre Sarrazac apresenta um estudo sobre aspectos recorrentes das escritas dramáticas, especialmente a partir da segunda metade do século XX. Os trabalhos de Sarrazac e de seus colaboradores (o teórico é também coordenador do Grupo de Pesquisas sobre o Drama da Universidade de Paris III) são atualmente uma referência fundamental para os estudos sobre dramaturgias, pois dialogam com a Teoria do Drama, Teoria da Literatura e Semiologia Teatral 
(entre outros campos), atualizando conceitos tradicionais e propondo noções novas para a abordagem das produções contemporâneas. Os estudos de Sarrazac e de seu grupo reconhecem o hibridismo das escritas dramáticas e os transbordamentos de gêneros, modelos e formas na atualidade. A questão levantada no final da citação acima - "Poder-se-á fixar, através do discurso crítico, o que existe apenas num estado incoativo, o que apenas teve tempo de começar?" (SARRAZAC, 2002, p. 23) - tem guiado não apenas Sarrazac como diversos pesquisadores que se preocupam em encontrar metodologias que deem conta da multiplicidade de epistemologias, poéticas e práticas dramatúrgicas.

A diversidade da produção atual desafia as iniciativas teóricas de generalização. Dramaturgo, teledramaturgo, roteirista, redator publicitário, designer de games - são diversos os ofícios que envolvem a escrita dramática - o teatro não é mais o único veículo do drama. Da mesma forma, o espetáculo teatral não corresponde mais, necessariamente, à tentativa de representação de um texto previamente escrito por um autor - nem a um formato pré-determinado de composição. A dramaturgia e o teatro, hoje, parecem gozar de total autonomia e de uma ampla plataforma de criação, com liberdade formal e temática inédita.

Porém, mesmo nesse contexto de grande abertura, em que se dá o desenvolvimento simultâneo de diferentes concepções de dramaturgia e tecnologias do espetáculo, é possível encontrar recorrências, não apenas uma série de particularidades. A pesquisa de doutorado que resultou na tese Dramaturgias de desvio: recorrências em textos encenados no Brasil entre 1995 e 2015 (SANCHES, 2016), desenvolvida no Programa de Pós-Graduação em Artes Cênicas da UFBA, por exemplo, identificou algumas recorrências em um corpus de cem peças, considerando os princípios formativos de suas intrigas em relação a alguns modelos tradicionais. A proposta foi contrapor os textos aos modelos e refletir, principalmente, sobre as estratégias dramatúrgicas que se desviam dos referenciais adotados.

A tese Dramaturgias de desvio partiu de um desejo semelhante ao do grupo francês: refletir sobre dramaturgias contemporâneas e contribuir para o mapeamento da produção recente sem, no entanto, aderir a um modelo idealizado de dramaturgia. A proposta foi reconhecer as reinvenções constantes e simultâneas do drama e olhar de maneira rizomática para essa realidade complexa e diversificada das práticas artísticas. O estudo recusou concepções teleológicas de dramaturgia, onde a morte de uma forma antiga engendraria uma forma nova, num movimento progressivo de "superação de modelos". Voltada mais às múltiplas e cambiantes conexões entre as expressões dramáticas do que a uma possível explicação totalizadora, ou à revelação de um eixo comum a todas elas, a pesquisa procurou compreender relações e particularidades, ao invés de buscar essências.

Das cem peças analisadas, vinte e duas são comentadas e citadas diretamente na tese. Além dessas, algumas peças de oito autores referenciais para a dramaturgia universal - Sófocles, Shakespeare, Racine, Strindberg, Pirandello, Brecht, Nelson Rodrigues e Beckett - são discutidas, ou mencionadas como exemplos de procedimentos dramatúrgicos. É importante destacar que a classificação proposta serviu apenas como um ponto de partida para as reflexões. A partir da classificação, foi possível identificar e discutir as recorrências e particularidades dos desvios observados, seus limites teóricos e problematizações: "Sem esquecer que a uma determinada peça pode corresponder uma combinação, um cruzamento de vários desvios [...]" (SARRAZAC, 2012, p.66.).

Inicialmente, os textos foram classificados em duas macrocategorias, relativas à estruturação da intriga. A primeira reúne as peças que apresentam aspectos mais identificados com as tradições. Foram considerados modelos tradicionais: drama aristotélico, neoclássico, hegeliano, melodrama, drama realista e naturalista. No total, vinte e três peças apresentaram características que estimulam comparações com essas referências.

A segunda macrocategoria reúne as dramaturgias de desvio. Essas peças apresentaram estruturas dramáticas que explicitam estratégias de relativização do sentido, que evidenciam sua autorreflexividade, diferenciando-se assim dos textos mais identificados com as tradições mencionadas, que tenderiam a construções mais fechadas - na medida em que demandariam um tipo menos explícito de colaboração 
da recepção. As dramaturgias de desvio, dramaturgias mais abertas, ou de perfil antiaristotélico (no sentido brechtiano), correspondem a um total de setenta e sete peças ( $77 \%$ dos textos levantados). $\mathrm{Ou}$ seja, as dramaturgias de desvio se mostraram predominantes na amostra e, por isso, acabaram por constituir o principal objeto da pesquisa. Concentrando-se nessas setenta e sete peças, a tese então propõe uma tipologia básica de desvios para diferenciar algumas estratégias autorreflexivas da produção selecionada. Essa tipologia, entretanto, não pretende limitar os textos a qualquer classificação. Como já foi afirmado, as categorias propostas pela pesquisa são aproximativas, e se constituíram em meio, não em fim, para uma reflexão sobre aspectos recorrentes das intrigas analisadas, servindo para identificar as diferentes tradições, ou os diversos tipos de desvios que podem formar um texto dramático.

Nesse sentido, os trabalhos de Sarrazac, de seus colaboradores e dos teóricos com os quais dialogam tornaram-se centrais para essa tentativa hesitante de abordagem das dramaturgias encenadas no Brasil nos últimos vinte anos. O estudo teve, na etapa do doutorado, a orientação da dramaturga, pesquisadora e professora da UFBA Cleise Mendes. O drama lírico (MENDES, 1981) e As estratégias do drama (MENDES, 1995), entre outros trabalhos de Mendes, também ajudaram a compor o referencial teórico da pesquisa. As noções de dialogismo e polifonia, conceitos formulados pelo linguista russo Mikhail Bakhtin, que são desenvolvidos e aplicados por Mendes no campo da dramaturgia, também foram fundamentais nesse processo.

A pesquisa começou em 2012, ainda no mestrado. Naquela etapa, a análise seguia fielmente a proposta metodológica de Sarrazac e de seu grupo: utilizar as noções de drama absoluto e crise do drama, formuladas por Peter Szondi (2011), porém, sem adotar a perspectiva teleológica do teórico húngaro, que via a emersão do épico nas formas dramáticas como possibilidade de resolução da suposta crise. A proposta dessa abordagem é apresentada no Léxico do drama moderno e contemporâneo (SARRAZAC, 2012), que reúne verbetes produzidos por Sarrazac e pesquisadores do grupo francês. O livro propõe uma revisão crítica da Teoria do drama moderno (SZONDI, 2011) de Peter Szondi sem abrir mão do conceito de "crise do drama", e substitui "[...] a ideia de um processo dialético com início, meio e, sobretudo, 'fim', pela ideia de uma crise sem fim, nos dois sentidos do vocábulo" (SARRAZAC, 2012, p. 32). A proposta mostrou-se muito operativa na medida em que, ao se comparar obras concretas com o modelo abstrato de drama absoluto, desvios são evidenciados e indicam caminhos para uma reflexão sobre o emergente na produção contemporânea. Da mesma forma, o procedimento também possibilita a identificação de desvios mesmo em peças consideradas clássicas.

$\mathrm{Na}$ etapa do doutorado, com o avanço da pesquisa e a ampliação tanto do conjunto de textos quanto do referencial teórico, foi possível manter os procedimentos comparativos, mas, ao invés de continuar adotando os conceitos de drama absoluto e de crise do drama, o estudo concentrou-se na noção de desvio. Observar os desvios das peças contemporâneas não apenas em relação ao modelo de drama absoluto de Szondi, mas em relação aos cinco modelos tradicionais já mencionados (drama aristotélico, neoclássico, hegeliano, melodrama, drama realista e naturalista) tornou-se o objetivo da pesquisa. Partese do princípio de que, não apenas esses, mas qualquer modelo pode ser considerado como referência (especialmente aqueles que correspondem aos hábitos majoritários de recepção) e servir à comparação com uma obra concreta. Entretanto, é necessário refletir sobre o modelo utilizado, qualquer que seja ele, para historicizá-lo, contextualizá-lo, e evitar generalizações abusivas. Pois, nesse processo, mais do que o julgamento dos desvios (ou dos modelos), importa a observação e reflexão sobre o que eles estariam indicando. Adota-se, assim, uma dinâmica que permite reconhecer a diversidade de modelos e práticas, sem tentar enquadrar as obras em poéticas específicas.

\section{O drama: acanônico por natureza}

Em O drama: acanônico por natureza, primeiro capítulo da tese Dramaturgias de desvio (SANCHES, 2016), são apresentadas as principais perspectivas teóricas do estudo. A expressão "acanônico por natureza" faz referência ao linguista russo Mikhail Bakhtin que afirma em Questões de Literatura e de estética: a teoria do romance (BAKHTIN, 2010) 
ser o romance o único gênero acanônico, diferentemente dos outros gêneros poéticos (épico, lírico e dramático "puros").

A romancização da literatura não implica em absoluto a imposição aos outros gêneros de um cânone estrangeiro e não peculiar, pois o próprio romance está privado deste cânone; ele, por sua natureza, é acanônico. Trata-se de sua plasticidade, um gênero que eternamente se procura, se analisa e que reconsidera todas as suas formas adquiridas. Tal coisa só é possivel ao gênero que é construído numa zona de contato direto com o presente em devir. (BAKHTIN, 2010, p. 427).

Não reconhecer a plasticidade dos outros gêneros é, de certa forma, confundir a abordagem rigorosa de alguns modelos idealizados com a diversidade e inventividade que as práticas artísticas, desde sempre, expressaram através das obras. Bakhtin, motivado talvez por seu recorte de análise, o romance, menospreza os outros gêneros, chegando a considerá-los com menor potencial dialógico. Nesse ponto, compartilhando a abordagem de Mendes (2010), o capítulo expõe a contradição de Bakhtin em relação a seu próprio conceito de dialogismo:

Trata-se [o dialogismo] de uma propriedade da língua em seu uso real, concreto, que leva todo falante a engendrar o seu discurso a partir do discurso de outro. Assim, por esse princípio, pode-se dizer que qualquer proferimento, qualquer ato de enunciação se faz em tensão dialógica com outros tantos, reproduzindo-os, citando-os, parafraseando-os, parodiando-os, negando-os, contrapondo-se a eles [...] Na história de suas formas, na sua relação com as instâncias de poder e com o público de cada tempo e espaço, o drama exibe vocação fortemente dialógica, avessa tanto à setorização ideológica (insiste no conflito de visóes, na contra- dicção) quanto à adesão irracional (exige debate, argumentação, disputa, julgamento) (MENDES, 2011, p.8-14).

Em seus estudos, Mendes opera com o conceito de dialogismo principalmente para análise do diálogo dramático. Já na tese Dramaturgias de desvio (SANCHES, 2016), a noção orienta não apenas as questões do diálogo dramático, mas toda a reflexão sobre aspectos estratégicos da composição dramatúrgica que respondem a diferentes tradições (e aos seus desvios). Dessa forma, a noção colabora para identificar vozes que atravessam as peças em todos seus elementos constitutivos: intrigas, personagens e discursos.

É a partir dessa perspectiva que, no mesmo capítulo, o conceito de drama absoluto de Peter Szondi (e, consequentemente, o conceito de crise do drama) é analisado. $\mathrm{O}$ objetivo é refletir sobre como o conceito szondiano de drama (adotado por Sarrazac e pelo grupo francês) sintetiza tradições e práticas distintas. Essa análise é um ponto estruturante da tese, que defende o desvio como vetor para um mapeamento da dramaturgia contemporânea.

\section{A teoria do drama moderno}

O conceito de drama formulado por Peter Szondi quer abranger uma multiplicidade de práticas dramatúrgicas, bem diversas, mas que teriam em comum a adoção de princípios aristotélicos, neoclássicos e hegelianos. É possível também identificar na noção de drama de Peter Szondi aspectos das concepções realista, naturalista e até melodramática. Ou seja, o conceito sintetiza diferentes poéticas, de tal forma que fica difícil encontrar alguma peça (por mais tradicional que seja) que se enquadre na formulação. Para Szondi, o drama moderno - o modelo de drama que é constituído a partir do Renascimento teria como horizonte atingir uma forma absoluta, ou "pura" (supostamente identificada com todos princípios canônicos, um drama absolutamente "dramático"). Para Szondi, o drama absoluto refletiria uma tendência de maior horizontalidade nas relações humanas, identificada com o fim da Idade Média e da 
perspectiva teocentrista. Em termos dramáticos, isso se traduziria numa ação que se desdobra por meio de personagens que representam homens capazes de decidir sobre seus destinos. Para essa concepção de drama, a ação dramática se desdobraria a partir de conflitos de interesses humanos, que se expressariam principalmente por meio do diálogo entre as personagens. Ecoa no discurso de Szondi a concepção hegeliana do gênero dramático como síntese do princípio lírico (interioridade) com o épico (ação manifesta no diálogo) e também a ideia de conflito como eixo da ação dramática.

O estabelecimento do diálogo como meio primordial da expressão dramática é também outro aspecto fundamental do drama, segundo Szondi. Sabe-se que, a partir do Renascimento, as dramaturgias tendem à supressão progressiva do prólogo, do coro e do epílogo.

Nisso o drama clássico se distingue tanto da tragédia antiga como da representação religiosa medieval, tanto do Theatrum mundi barroco como das peças históricas de Shakespeare. A supremacia absoluta do diálogo, ou seja, daquilo que se pronuncia no drama entre homens, espelha o fato de este se constituir exclusivamente com base na reprodução da relação inter-humana e só conhecer o que nessa esfera reluz (SZONDI, 2011,

Szondi deixa clara a especificidade de sua noção de drama, que exclui a tragédia grega, os dramas medievais, as peças de Shakespeare, o barroco espanhol, mas não exemplifica, com uma única obra sequer, sua concepção de drama moderno, ou absoluto. Para o autor, o drama é uma dialética fechada em si mesma, livre para ser, a cada momento, novamente fundada. Em síntese, o drama seria uma sequência de momentos presentes: “[...] O drama é absoluto. Para ser pura relação, para poder, em outras palavras, ser dramático, ele deve desvencilhar-se de tudo o que lhe é exterior. O drama não conhece nada fora de si. (SOZNDI, 2011, p.25)". Também podemos identificar nessa característica ecos da dialética hegeliana e da concepção aristotélica (ausência aparente do dramaturgo, relativa autonomia das personagens, desdobramento causal e concentrado da ação).
O dramaturgo está ausente do drama. Ele não fala, institui o que se pronuncia. O drama não é escrito, antes posto. Nele, todas as palavras ditas são "de-cisões': nascidas da situação, nela permanecem, não devendo de forma alguma ser acolhidas como palavras que emanam do autor (SZONDI, 2011, p.25).

A postura de silenciosa observação do público deveria ser revertida em um jogo dramático de identificação e ilusionismo, onde a relação espectadordrama conheceria apenas a separação completa, ou a total identidade - ideia que podemos associar ao realismo, ao naturalismo e também ao melodrama. Sobretudo porque a tragédia neoclássica tem diversos artifícios "embelezadores da realidade", entre eles, a linguagem das personagens, versificada com rima. Sob a perspectiva atual, é difícil imaginar uma identificação plena (nos sentidos mais naturalista e melodramático) do leitor/espectador com aquela linguagem tributária do "decoro" e com alto grau de estilização. Assim, o conceito de drama absoluto de Szondi, embora diretamente relacionado ao neoclassicismo, em diversos pontos nos quais defende uma identificação "absoluta” entre recepção e obra, parece mais abordar as heranças realista, naturalista e, relativamente, também melodramática.

Outro exemplo está na relação ator e personagem proposta pelo modelo. Também nesse aspecto é possível perceber a inclinação realista e/ou naturalista da concepção de drama de Szondi. O autor afirma que o ator deveria confundir-se com seu papel, identificar-se totalmente com sua personagem "[...] Nele [o drama absoluto] a relação da arte do ator e seu papel não deve de modo algum ser visível; pelo contrário, ator e figura-dramática precisam fundirse para que o homem do drama surja" (SZONDI, 2011, p.26).

Szondi ainda se refere ao drama absoluto como sendo de caráter primário e, a partir dessa reflexão, defende mais dois princípios que, esses sim, podemos associar às regras neoclássicas: as unidades de tempo e lugar. 
A natureza absoluta do drama pode ser formulada do seguinte modo: o drama é primário. Ele não é a exposição (secundária) de algo (primário), mas põe a si próprio em cena, é sua própria encenação. [...] Sendo o drama sempre primário, seu tempo é sempre o presente. O que não se traduz em absoluto numa situação estática, mas apenas no modo particular do decurso temporal dramático: o presente passa e se torna passado, mas enquanto passado não se faz mais presente em cena. Ele passa na medida em que traz consigo mudanças, na medida em que um novo presente surge de sua antítese. [...] Um raciocínio análogo em relação ao espaço justifica a exigência de uma unidade de lugar. [...] Ademais a descontinuidade espacial (como a temporal) também pressupõe o eu épico [...] (SZONDI, 2011, p. 26-28).

Definido o drama, Szondi passa a comentar aspectos formais, presentes em obras dramáticas produzidas entre 1880 e 1950 , os quais problematizariam, ou simplesmente não corresponderiam mais a essas concepções dramáticas. O fenômeno, que evidenciaria a emergência de novos conteúdos e a demanda por novas expressões formais, é definido pelo autor como "crise do drama" - no caso, a crise do drama absoluto, o modelo de forma dramática inferido das práticas europeias entre os séculos XVII e XIX. Como foi mencionado anteriormente, Szondi não apresenta sequer um exemplo de texto que consideraria como um drama absoluto, mas dá muitos exemplos de textos que contrariam as concepções absolutas do drama, Teoria do drama moderno (SZONDI, 2011) é composto, majoritariamente, por esses comentários. A noção de drama absoluto, portanto, é operativa por meio da contraposição de obras dramáticas às suas concepções (as quais reuniriam as ideias e procedimentos das principais correntes tradicionais). Nessa perspectiva, o método de Szondi continua útil atualmente, pois é possível escolher textos de qualquer época e observar-lhes os desvios, ou seja, aqueles aspectos que diferem das concepções "absolutas" e indicam estratégias de autorreflexividade. Isto não significa admitir a existência de um drama realmente absoluto, muito menos nos estabelecer as tradições como critério de valor. A ideia é justamente tentar interpretar que conteúdos formais, ou quais possibilidades de sentido esses desvios estariam indicando - e conferir-lhes uma formulação teórica.

O único inconveniente metodológico é adotar um modelo que associa o drama a uma única forma, por demais conservadora e abstrata, o que pode estimular o não reconhecimento das múltiplas tradições e, consequentemente, das múltiplas vozes que ecoam na história da dramaturgia. Ao ignorar-se a diversidade das tradições, tende-se a ignorar também a diversidade de seus desvios. O conceito de drama absoluto de Szondi é uma tentativa de sintetizar num único modelo uma série de práticas muito diferentes. Os parâmetros e convenções dramáticas que imperam no final do século XIX não resumem toda a diversidade das dramaturgias que começaram a se estabelecer a partir do período renascentista na Europa e vão se desdobrando até a contemporaneidade - menos ainda a história da dramaturgia como um todo.

Embora defenda a diversidade e permanente transformação do drama, criticando aqueles que, como o teórico alemão Hans-Thies Lehmann em Teatro Pós-Dramático (LEHMANN, 2007), condenam o drama ao passado e declaram sua morte, ou propõem sua negação, ainda assim, Sarrazac opera com esse modelo de drama absoluto, ao qual ele também se refere como modelo "aristotélico-hegeliano".

Talvez seja uma contradição defender a multiplicidade das formas dramáticas e adotar esse conceito operativo, na medida em que ele associa o gênero dramático a um único modelo (e tão abstrato que não há um exemplo de peça que se enquadre nele), o que acaba endossando a ideia de drama como uma forma específica (idealizada, canônica, ou conservadora) e não como prática artística, fazer criativo dialógico, modo de escrita que se transforma e em tempo algum correspondeu a um modelo único e unívoco.

Nessa perspectiva, a proposta de utilização da noção de desvio como vetor para a abordagem das escritas dramáticas (no lugar da noção de crise do drama) se configura como uma das principais con- 
tribuições teóricas da tese Dramaturgias de desvio, embora o procedimento de análise e a própria noção de desvio sejam defendidos e teorizados por Sarrazac:

Um estudo aprofundado desses extraordinários canteiros de obra de formas experimentais constituídos por peças igualmente dependentes da montagem, como O sonho, de Strindberg, ou O sapato de cetim, de Claudel (o qual coloca justamente na epígrafe de sua obra um provérbio português: "Deus escreve certo por linhas tortas"), certamente nos permitirá efetuar um vasto inventário das formas-desvios no teatro do século XX. [...] Numa época em que a noção de gênero codificado - comédia, tragédia, féerie, farsa etc. - parece ter-se tornado obsoleta ou paradoxal [...] talvez pudéssemos visar uma tipologia dos desvios - essas formas que deformam, essas deformações que informam - no teatro moderno e contemporâneo (SARRAZAC, 2012, p.65-66).

Como é possível reconhecer na citação acima, o que a pesquisa fez foi aceitar a proposta de Sarrazac de mapear as dramaturgias contemporâneas, compondo uma "tipologia dos desvios". O próprio Léxico do drama moderno e contemporâneo (SARRAZAC, 2012) pode ser encarado como resultado de um esforço coletivo nesse sentido, porém, voltado para as dramaturgias encenadas na Europa. A particularidade da tese brasileira é, sobretudo, a concentração do recorte em dramaturgias encenadas no Brasil no início do século XXI, e o afastamento da noção de crise do drama absoluto.

\section{Os desvios recorrentes}

Sobre os textos classificados como dramaturgias de desvio, a maioria foi considerada de tendência épica: dos 77 textos, 52 apresentaram estruturas associadas a emersões épicas do drama. As noções de montagem/colagem, metadrama e rapsódia foram utilizadas para designar essas recorrências de desvios épicos identificados pela pesquisa. Do total de 52 textos, 12 são compreendidos como montagens/ colagens, 19 como metadramas e 21 como rapsódias. A tese aborda cada um desses desvios e discute as recorrências com variados exemplos de peças destacando sempre o caráter aproximativo das categorias. Essas noções dialogam não apenas com os trabalhos de Peter Szondi e Sarrazac, mas com uma ampla perspectiva sobre o drama que associa determinadas estratégias ao modo épico - o dramaturgo e encenador alemão Bertolt Brecht é um dos exemplos mais célebres nesse contexto. As teorizações de Brecht sobre o Teatro Épico e, particularmente, sobre os procedimentos de distanciamento da "dramaturgia não-aristotélica" (termo que usou para designar sua produção dramatúrgica) foram fundamentais para a análise das estratégias que a pesquisa qualifica como épicas. A tese parte de um levantamento dos principais aspectos estruturais das peças de Brecht, mencionado pelo teórico Gerd Bornheim no livro Brecht: a estética do teatro (BORNHEIM, 1992). Apresentados e discutidos no segundo capítulo da tese, esses procedimentos são considerados como desvios épicos:

\begin{abstract}
Relativização, ruptura, distanciação [sic], decisões e continuação - tais são os recursos que Brecht emprega para conseguir realizar o efeito de distanciamento em sua dramaturgia. Evidentemente, esses instrumentos não devem ser entendidos cada um por si mesmo; cada um, tomado em si mesmo, é incompleto, e os tópicos analisados forçam um tanto as composições brechtianas. São instrumentos que se condicionam uns aos outros, entrecruzam-se, correspondem-se em grau maior ou menor (BORNHEIM, 1992, p. 328-329).
\end{abstract}

Porém, a maior contribuição da tese talvez esteja justamente na reflexão sobre os 25 textos restantes: as dramaturgias de desvio de inclinação lírica.

Assim como fez em relação aos procedimentos de tendência épica, a tese também abordou os desvios de inclinação lírica em três categorias recorrentes na amostra. São elas: Monodrama (que inclui a 
subcategoria Jogo de Sonho), Poema Dramático e Ação Cíclica. As primeiras, assim como as três categorias de desvios épicos abordadas, são objeto de verbetes específicos no Léxico, além de serem desenvolvidas em outros escritos de Sarrazac como $O f u$ turo do drama (SARRAZAC, 2002) e Sobre a fábula e o desvio (SARRAZAC, 2013). Já a última categoria, a Ação Cíclica, é uma formulação própria do estudo, desenvolvida em diálogo com os estudos de Cleise Mendes (1981) e de Gil Vicente Tavares (2011), pesquisador, diretor e dramaturgo baiano, autor de $\mathrm{A}$ herança do absurdo (TAVARES, 2015), que trata da influência das peças de absurdo nas dramaturgias contemporâneas.

\section{Os desvios líricos e o futuro do drama}

Algumas das características tradicionalmente associadas ao gênero lírico são utilizadas como referência para definir o que o estudo considera como emersões líricas do drama. O teórico Anatol Rosenfeld (2010), partindo do princípio de que não existem formas absolutas - portanto, não existe um poema absolutamente lírico, um drama totalmente dramático, ou uma narrativa completamente épica - sintetiza alguns aspectos que servem como referenciais:

Trata-se essencialmente da expressão de emoções e disposições psíquicas, muitas vezes também de concepções, reflexões $e$ visões enquanto intensamente vividas e experimentadas. A Lírica tende a ser a plasmação imediata das vivências intensas de um Eu no encontro com o mundo, sem que se interponham eventos distendidos no tempo (como na Épica e na Dramática) [...] Quanto mais os traços líricos se salientarem, tanto menos se constituirá um mundo objetivo, independente das intensas emoções da subjetividade que se exprime. Prevalecerá a fusão da alma que canta com o mundo, não havendo distância entre sujeito $e$ objeto. [...] À intensidade expressiva, $\grave{a}$ concentração e ao caráter "imediato" do poema lírico, associa-se, como traço estilístico importante, o uso do ritmo e da musicalidade das palavras e dos versos. De tal modo se realça o valor da aura conotativa do verbo que este muitas vezes chega a ter uma função mais sonora que lógico-denotativa. (ROSENFELD, 2010, p.22-23).

Nessa perspectiva, qualidades como subjetividade, musicalidade, expressão de emoções e sentimentos, desreferencialização de tempo e espaço, intensidade, concentração e brevidade são associadas à uma ideia geral e abstrata de construção lírica "pura", ou "absoluta". Outro ponto levantado na tese é o fato da concepção de drama de Hegel (que tem uma influência evidente no conceito de drama absoluto de Szondi) atribuir o caráter lírico do drama à interioridade das personagens, suas motivações, sentimentos, pensamentos, subjetividades. Nessa concepção, estratégias como o monodrama e, entre elas, o jogo de sonho, seriam evidentemente procedimentos estruturais (dramatúrgicos) de cunho lírico, pois apresentariam os acontecimentos sob uma perspectiva subjetiva - a partir da imaginação e da percepção de uma personagem, ou de um scriptor específico (correspondentes ao "eu lírico" de um poema). Ao invés de apresentar os acontecimentos como resultados da dialética entre as "subjetividades" das personagens, suas expressões, confrontos e objetivizações em ação dramática, todos os discursos e referenciais são subjetivados, relativizados, adquirindo certo caráter instável, simbólico, ou de fantasia - de sonho.

Já a mencionada Ação Cíclica, outro procedimento de cunho lírico identificado pela pesquisa, estaria fundamentada, sobretudo, em uma dinâmica de repetição - característica formal atribuída tradicionalmente ao poema lírico. O termo cíclico, no entanto, ressaltaria tanto a possibilidade de uma repetição em diferença, numa dinâmica de espiral infinita, como também de repetição mecânica e opressiva, ambas muito presentes nas dramaturgias contemporâneas.

A noção de Poema Dramático também é abordada com essa perspectiva, e tem a particularidade de ser associada a apenas um texto do corpus de 100 peças da pesquisa. É a noção mais controversa, pois 
indica um tipo de construção limítrofe entre peça e poema que, embora não muito recorrente na amostra, é muito frequente nos palcos e em trabalhos teóricos sobre dramaturgia.

Nesse capítulo da tese, Nelson Rodrigues, um dos dramaturgos brasileiros mais polêmicos do século XX, é citado como autor de peças caracterizadas por uma potente emersão da subjetividade, associada muitas vezes a estratégias expressionistas, e que serve como exemplo de muitos desvios líricos abordados (e emblemáticos). Alguns aspectos desses desvios são observados em textos de prestigiados autores contemporâneos como João Falcão, Bosco Brasil, Jô Billac e Grace Passô, entre outros citados no referido capítulo.

Os textos, estratégias e autores que são associados às recorrências de desvios líricos, mesmo correspondendo a apenas $25 \%$ do corpus de textos, são apresentados pela tese como determinantes para o processo de transformação do drama, além de indicativos de um caminho ainda latente de estudo e compreensão. Diante da exaustiva exploração das teorias épicas de teatro e dramaturgia durante o século XX, a associação de determinadas estratégias ao modo lírico e a afirmação da subjetividade como agente transformador (tantas vezes rotulada como "subjetivismo" e desqualificada como "alienação") podem ser encaradas como mais uma contribuição particular da tese Dramaturgias de desvio e indicar, junto com a noção de desvio, caminhos possíveis para o mapeamento do drama contemporâneo e o desdobramento de novas pesquisas. 


\title{
REFERÊNCIAS
}

BAKHTIN, Mikhail. Questões de literatura e de estética: a teoria do romance. São Paulo: Hucitec, 2010.

BORNHEIM, Gerd Alberto. Brecht: A estética do teatro. Rio de Janeiro: Graal, 1992.

MENDES, Cleise Furtado. As estratégias do drama. Salvador: Centro Editorial e Didático da UFBA, 1995.

. Diálogo e performatividade no drama. In: Revista Tabuleiro de Letras. Salvador: Programa de Pós-Graduação em Estudos da Linguagem da UNEB, 2011. Disponível em: http://www.revistas.uneb.br/index.php/tabuleirodeletras/article/ view/153/104 Acesso em: 11 de dezembro de 2016.

. O drama lírico. ART. 002, Salvador: 47-67, jul./set., 1981.

ROSENFELD, Anatol. O teatro épico. São Paulo: Perspectiva, 2010.

SANCHES, João. Dramaturgias de desvio: recorrências em textos encenados no Brasil entre 1995 e 2015. 2016. 251 p. Tese (doutorado) - Universidade Federal da Bahia, Escola de Teatro, Salvador, Bahia.

SARRAZAC, Jean-Pierre et al. (Org.). Léxico do drama moderno e contemporâneo. São Paulo: Cosac Naify, 2012.

O futuro do drama. Porto: Campos das Letras, 2002.

Sobre a fábula e o desvio. : Rio de Janeiro: 7Letras: Teatro do Pequeno Gesto, 2013.

SZONDI, Peter. Teoria do drama moderno (1880-1950). São Paulo: Cosac Naify, 2011.

TAVARES, Gil Vicente Barbosa de Marques. A herança do absurdo: vestígios no drama contemporâneo. Salvador: EDUFBA, 2015.

\begin{abstract}
The article presents a synthesis of the thesis Dramaturgias de desvio: recorrências em textos encenados no Brasil entre 1995 e 2015, a comparative study of one hundred pieces staged in cities of different brazilian regions. The text exposes the main topics of the research and its theoretical perspectives, with the purpose of proposing ways to the mapping of the contemporary dramaturgical production.
\end{abstract}

\section{KeYwORDS}

Dramaturgy; Detour; Contemporary scene. 